\title{
General Practitioners' views and experiences on the barriers and facilitators that men who have sex with men have when accessing primary care for HIV testing and sexual health screening
}

\author{
Steven Maxwell \\ Senior Teaching Fellow, King's College London, London SE1 8WA
}

\begin{abstract}
Aim: This study's objectives were to collate General Practitioners' (GPs) views and experiences on the barriers and facilitators for providing HIV and sexual health screening in primary care to men who have sex with men. Background: Men who have sex with men (MSM) are disproportionately effected by sexually transmitted infections and HIV. Some MSM may not attend for testing and primary care may come in contact with this group. There may be varying barriers for MSM accessing services. Primary care can provide an opportunity to offer testing but with limited GPs views on this topic, it is important to understand the potential barriers and facilitators. Method: A structured online survey was used to gather data and the survey link was emailed to all General Practices in the City of Edinburgh. The total available sample of GPs was 485. The survey used a combination of multiple choice questions and Likert scales rating from 1 to 5 . Friedman's two-way analysis of variation rank was used for data analysis. Findings: In total, 62 GPs from the City of Edinburgh completed the survey with the majority of the sample having over 10 years' experience in primary care. The most significant barrier was patient preference to access specialist services. The highest rated method to promote HIV and sexual health screening was the use of external promotion.
\end{abstract}

Key words: barriers sexual health; HIV; MSM; primary care

Received 5 December 2016; revised 24 May 2017; accepted 27 August 2017;

first published online 2 November 2017

\section{Introduction}

In the United Kingdom there is a higher prevalence of sexually transmitted infections (STIs) in the men who have sex with men (MSM) population than compared with the general population (Cohen et al., 2013). The United Kingdom has in excess of 107000 people currently living with HIV

Correspondence to: S. Maxwell, Senior Teaching Fellow, King's College London, James Clerk Maxwell Building, 57 Waterloo Road, London SE1 8WA. Email: steven.maxwell@kcl.ac.uk

${ }^{a}$ Senior Teaching Fellow, Florence Nightingale Faculty of Nursing and Midwifery, James Clerk Maxwell Building, 57 Waterloo Road, London SE1 8WA, UK. and of this number MSM is thought to account for around 40\% (Public Health England, 2014). A study of MSM attending gay commercial venues in Scotland's busiest urban centres indicated through anonymous HIV testing that the prevalence level of HIV was $4.8 \%$, and $25 \%$ of the men who tested positive were not aware of their positive HIV status (Wallace and McDaid, 2014).

England's gay men sex survey (2014) indicates that one in four MSM have never had an HIV test (Sigma Research, 2016). Evidence suggests that there is a significant number of MSM who have never accessed HIV testing at sexual health services and others who only attend on an infrequent and occasional basis (Wood et al., 2011). 
The National Institute for Clinical Excellence (NICE, 2010) emphasis the important role that primary care can provide in the provision of HIV testing for MSM who may be at higher risk.

Previous UK literature from GPs on this topic is limited. This study's objectives were to collate GPs views and experiences on the barriers MSM may have when being offered HIV and sexual health screening in primary care. This included understanding what facilitators might aid in promoting MSM HIV and sexual health screening.

\section{Method}

The study was set within the City of Edinburgh, which has a total of 72 general practices comprising $\sim 485$ GPs. The data were collected by a structured questionnaire hosted on Survey Monkey which was sent out using a hyperlink via email to all GP practice managers in the City of Edinburgh. The email requested that the practice managers forward it to all the GPs in the practice. The survey aimed to determine the primary care experience of the sample, estimate the number of MSM HIV tests GPs offered or completed and elicit the GPs' views on potential barriers and facilitators in providing MSM HIV and sexual health screening in primary care. The survey questions required answers in fivepoint Likert scales and multiple choice options. The questions were developed from barriers and facilitators highlighted in published literature. Summary descriptive analysis was exported from Survey Monkey. Analyses of the distributions of the Likert scale item responses were conducted using a series of related samples Friedman's two-way analysis of variance by rank using the Statistical Package for the Social Sciences v23.

\section{Results}

In total, 62 GPs responded to the survey ( 13\% response rate) and the majority of the sample had over 10 years experience in primary care $(68 \%$ over 10 years, $13 \%$ between 5 and 10 years and $19 \%$ under five years). There were similar numbers of responses from all four geographical areas of Edinburgh [South East Edinburgh - 27.4\% (17), South West Edinburgh - 22.5\% (14), North East Edinburgh - 27.4\% (17) and North West Edinburgh - 22.5\% (14)]. In total, $89 \%$ of respondents had discussed or completed an HIV test with MSM less than five times in the previous three months and $11 \%$ between five and ten times in that period. The sample reported none of their practices asked sexual orientation at patient registration and only one asks about partner gender.

\section{Barriers}

The survey set out six main barriers for MSM accessing HIV and sexual health screening in

Table 1 Rate from 1 to 5 in the following statements, what you believe may be barriers for men who have sex with men accessing primary care for HIV testing and sexual health screening

\begin{tabular}{|c|c|c|c|c|c|c|c|}
\hline Barriers & $\begin{array}{l}1: \text { not a } \\
\text { barrier }\end{array}$ & 2 & 3 & 4 & $\begin{array}{l}\text { 5: a common } \\
\text { barrier }\end{array}$ & Median & $N$ \\
\hline $\begin{array}{l}\text { Patient is not aware of HIV testing and } \\
\text { sexual health screening being } \\
\text { available in primary care }\end{array}$ & $\begin{array}{l}16 \\
(25.8 \%)\end{array}$ & $\begin{array}{l}11 \\
(17.7 \%)\end{array}$ & $\begin{array}{l}16 \\
(25.8 \%)\end{array}$ & $\begin{array}{l}13 \\
(21.0)\end{array}$ & $\begin{array}{l}6 \\
(9.75 \%)\end{array}$ & 3.00 & 62 \\
\hline $\begin{array}{l}\text { Partner gender/sexual orientation is } \\
\text { not known to the GP or practice }\end{array}$ & $\begin{array}{l}9 \\
(14.5 \%)\end{array}$ & $\begin{array}{l}5 \\
(8.1 \%)\end{array}$ & $\begin{array}{l}15 \\
(24.2 \%)\end{array}$ & $\begin{array}{l}20 \\
(32.3 \%)\end{array}$ & $\begin{array}{l}13 \\
(21.0 \%)\end{array}$ & 4.00 & 62 \\
\hline $\begin{array}{l}\text { Men have never been asked about } \\
\text { sexual orientation/partner gender }\end{array}$ & $\begin{array}{l}8 \\
(12.9 \%)\end{array}$ & $\begin{array}{l}8 \\
(12.9 \%)\end{array}$ & $\begin{array}{l}16 \\
(25.8 \%)\end{array}$ & $\begin{array}{l}20 \\
(32.3 \%)\end{array}$ & $\begin{array}{l}10 \\
(16.1 \%)\end{array}$ & 3.00 & 62 \\
\hline $\begin{array}{l}\text { Patient concern about confidentiality in } \\
\text { medical notes and associated stigma }\end{array}$ & $\begin{array}{l}4 \\
(6.5 \%)\end{array}$ & 7 & $\begin{array}{l}23 \\
(37.1 \%)\end{array}$ & $\begin{array}{l}20 \\
(32.3 \%)\end{array}$ & $\begin{array}{l}8 \\
(12.9 \%)\end{array}$ & 3.00 & 62 \\
\hline $\begin{array}{l}\text { Patient preference to access specialist } \\
\text { services }\end{array}$ & 3 & $\begin{array}{l}4 \\
(6.5 \%)\end{array}$ & $\begin{array}{l}20 \\
(32.3 \%)\end{array}$ & $\begin{array}{l}21 \\
(33.9 \%)\end{array}$ & $\begin{array}{l}14 \\
(22.6 \%)\end{array}$ & 4.00 & 62 \\
\hline $\begin{array}{l}\text { Patient view about primary care not } \\
\text { fully understanding the issues related } \\
\text { to men to have sex with men }\end{array}$ & $\begin{array}{l}7 \\
(11.3 \%)\end{array}$ & $\begin{array}{l}8 \\
(12.9 \%)\end{array}$ & $\begin{array}{l}21 \\
(33.9 \%)\end{array}$ & $\begin{array}{l}21 \\
(33.9 \%)\end{array}$ & $\begin{array}{l}5 \\
(8.1 \%)\end{array}$ & 3.00 & 62 \\
\hline
\end{tabular}


primary care and asked the sample to rate the items on a five-point rating scale from 1 (not a barrier) to 5 (a common barrier). The responses are shown in Table 1. The distribution of responses to the six barrier items differed significantly from each other (related samples Friedman's two-way analysis of variance by rank test: $\chi^{2}=22.8, \mathrm{df}=5$, $P<0.001)$. Visual inspection of the rating scales shows that one particular barrier (MSM may not be aware that HIV testing and sexual health screening is available in primary care) has a notably higher level of responses at the lower end of the scale (1-2) than compared with the other barriers. Further analysis after exclusion of this particular barrier showed no significant difference between the distributions of the five other barriers (related samples Friedman's two-way analysis of variance by rank test: $\chi^{2}=6.6, \mathrm{df}=4, \mathrm{~ns}$ ).

\section{Methods to promote uptake}

The sample were asked what methods they think would be effective in promoting an increase in the uptake of MSM having HIV testing and sexual health screening in primary care. This was asked using a five-point rating scale from 1 (not useful) to 5 (very useful) and included four methods. An overview of the responses is shown in Table 2.

The distribution of responses for the four methods of uptake differed significantly from each other (related samples Friedman's two-way analysis of variance by rank test: $\chi^{2}=47.7, \mathrm{df}=3$, $P<0.001)$. Further analysis showed that external promotion of HIV/STI screening (eg, posters/ leaflets in MSM-related venues) was viewed as a more effective method to promote uptake (related samples Friedman's two-way analysis of variance by rank test: $\left.\chi^{2}=16.9, \mathrm{df}=2, P<0.001\right)$, and asking sexual orientation at new patient registration and offering targeted HIV testing to people at higher risk a less effective method (related samples Friedman's two-way analysis of variance by rank test: $\left.\chi^{2}=21.2, \mathrm{df}=2, P<0.001\right)$ than the other two methods, which were themselves statistically indistinguishable (related samples Friedman's two-way analysis of variance by rank test: $\chi^{2}=2.5$, $\mathrm{df}=1, \mathrm{~ns})$.

\section{Discussion}

The promotion of the study was reliant on practice managers sending the survey emails on to GPs and the GPs self-selected to participate. Due to resource limitations and availability of practice managers' contact details, email was deemed to be the most effective promotional method. Due to limitations placed on ethical approval no personal demographic information could be collated.

The GPs in this study demonstrate clearly they believe MSM prefer to access specialist services and view low awareness of HIV and sexual health screening being available in primary care as the least problematic barrier. Koester et al. (2013) found in a qualitative study from the United States that some MSM may prefer accessing specialist services as it provides anonymity and there still exists stigma around an HIV test being in medical records. A UK-based study of gay and bisexual

Table 2 Rate from 1 to 5, what methods you think would be useful and effective in increasing the uptake of men who have sex with men (MSM) having HIV testing and sexual health screening in primary care

\begin{tabular}{|c|c|c|c|c|c|c|c|}
\hline Methods & $\begin{array}{l}\text { 1: not } \\
\text { useful }\end{array}$ & 2 & 3 & 4 & $\begin{array}{l}\text { 5: very } \\
\text { useful }\end{array}$ & Median & $N$ \\
\hline $\begin{array}{l}\text { Promotion of same sex HIV/STI screening and equality policy in } \\
\text { primary care premises (eg, same sex posters and leaflets) }\end{array}$ & $\begin{array}{l}2 \\
(3.2 \%)\end{array}$ & $\begin{array}{l}6 \\
(9.7 \%)\end{array}$ & $\begin{array}{l}16 \\
(25.8 \%)\end{array}$ & $\begin{array}{l}24 \\
(38.7 \%)\end{array}$ & $\begin{array}{l}14 \\
(22.6 \%)\end{array}$ & 4.00 & 62 \\
\hline $\begin{array}{l}\text { Asking sexual orientation at new patient registration and } \\
\text { offering targeted HIV testing to people at higher risk }\end{array}$ & $\begin{array}{l}18 \\
(29.0 \%)\end{array}$ & $\begin{array}{l}13 \\
(21 \%)\end{array}$ & $\begin{array}{l}11 \\
(17.7 \%)\end{array}$ & $\begin{array}{l}13 \\
(21 \%)\end{array}$ & 7 & 2.50 & 62 \\
\hline $\begin{array}{l}\text { Offering universal HIV testing to every new registration aged } \\
16-59\end{array}$ & $\begin{array}{l}12 \\
(19.4 \%)\end{array}$ & $\begin{array}{l}11 \\
(17.7 \%)\end{array}$ & 9 & $\begin{array}{l}14 \\
(22.6 \%)\end{array}$ & $\begin{array}{l}16 \\
(25.8 \%)\end{array}$ & 3.00 & 62 \\
\hline $\begin{array}{l}\text { External promotion of HIV/STI screening being available in } \\
\text { primary care (eg, posters/leaflets in non-primary care premises } \\
\text { and MSM-related venues) }\end{array}$ & $\begin{array}{l}1 \\
(1.6 \%)\end{array}$ & $\begin{array}{l}2 \\
(3.2 \%)\end{array}$ & $\begin{array}{l}8 \\
(12.9 \%)\end{array}$ & $\begin{array}{l}27 \\
(43.5 \%)\end{array}$ & $\begin{array}{l}24 \\
(38.7 \%)\end{array}$ & 4.00 & 62 \\
\hline
\end{tabular}

$\mathrm{STI}=$ sexually transmitted infections 
men found there was a fear of the sample disclosing same sex relations to primary care professionals for fear of same sex stigma and this was compounded with the lack of clear same sex health promotion strategies in GP practices (Cant, 2002). The GPs' perceptions of MSM preferring to access specialist services would appear consistent with other studies using MSM as samples. Evidence indicates that there is still a proportion of the MSM population who have not engaged with specialist sexual health services (Wood et al., 2011). For this group of MSM, primary care can offer an accessible and opportunistic testing service as they may attend the GP for other health reasons (NICE, 2012).

Evidence mentioned previously indicates some MSM may prefer to access specialist services because of stigma. Kober et al. (2010) found some HIV-positive MSM presented late for HIV testing because of stigma connected to a test and the potential health and social consequences that can go with a positive HIV status. The GPs rated the issue of patient concern about confidentiality in medical notes and the associated stigma to be significant but no different from the other barriers. A qualitative study of 32 MSM found that the sample had fear on the potential impact an HIV test may have being in medical records but a perceived advantage of primary care was having an established therapeutic relationship with the GP (Koester et al., 2013). This study's results demonstrates consistency between GPs and MSM perceptions which generally shows ongoing issues around HIV-related stigma. It may be beneficial to do more in depth exploration with GPs on HIV-related stigma and identify any potential measures that may aid in reducing this as a barrier for MSM accessing primary care.

This sample of GPs viewed internal and external promotion of primary care-based HIV testing and sexual health screening as the most effective methods to promote uptake.

A UK-based study of gay and bisexual men found that primary care promotion of same sex health issues would encourage gay and bisexual men to be more open with their GPs about sexual health matters (Cant, 2002). This type of promotion could act as a facilitator for some MSM to be more proactive in engaging with their GP for sexual health screening. External promotion with the use of leaflets and posters in MSM and Lesbian, Gay and Transgender venues may potentially be a

Primary Health Care Research \& Development 2018; 19: 205-209 useful strategy but without a rigorous and targeted campaign this actual benefits are unknown. This could potentially have resource implications for primary care but the demand would be unknown as earlier evidence indicates some MSM prefer to access specialist services. The use of same sex literature in waiting areas, diversity statements given at patient registration and equality and diversity material in waiting areas could be acceptable and feasible measures to internally promote MSM sexual health issues in primary care premises. It could be advantageous to engage with the wider GP population to explore if there is current use of same sex promotional materials and help understand the practicality of implementing these types of strategies.

The GPs rated the two testing regimes lowest in usefulness to increase uptake but universal HIV testing for all new adult patients was rated a more effective method than targeted MSM HIV testing. The British HIV Association (BHIVA) (2008) suggests that primary care should consider offering an HIV test to every new patient registration if the local populations diagnosed HIV prevalence rate is more than two cases per thousand. The majority of the sample do not ask sexual preference or partner gender at patient registration and new patient appointment policy varies across primary care. Lack of awareness of sexual orientation is linked to lower rates of HIV screening (Petroll and Mosack, 2011). Lowe and Huebner (2010) found there was an increased rate of testing if the GP had an open and established relationship with the patient. Routine risk at GP patient registration is a viable tool to increase high-risk group identification and reduce late HIV diagnosis (Health Protection Agency, 2011). System and resource issues around patient registration could potentially make HIV testing guidance challenging to implement. It may be appropriate to engage further with primary care to explore this and for each service to individually adopt a suitable screening strategy.

\section{Conclusion}

The GPs identified a few of the survey options to be barriers for MSM uptake of primary care-based HIV and sexual health screening with patient preference to access specialist services the highest rated barrier. The GPs viewed external promotion 
of HIV and sexual health screening as being the most useful. There are limitations in interpreting how representative these results are of the wider GP population although the main findings show consistency with previous research.

Offering HIV testing at patient registration, as recommended by BHIVA and NICE, can help to identify higher risk MSM and engage them effectively with in a primary care service model. A consistent external and internal promotion strategy for MSM HIV and sexual health screening could be a practical tool to increase the inclusivity of primary care in same sex relationship topics.

Specialist sexual health services remain central to the provision of MSM sexual health screening but it is important to recognise the role GPs can provide. Widening of primary care delivery would promote equity of service access and potentially assist in promoting increased testing for higher risk MSM groups.

\section{Acknowledgements}

The author gratefully acknowledge the support of Dr Ewen Stewart (NHS Lothian) and the GPs who contributed to the survey.

\section{Ethical Standards}

Full ethical approval was provided by NHS Lothian's Quality Improvement Body and Queen Margaret University Ethics Board.

\section{Conflicts of Interest}

There are no conflicts of interest.

\section{References}

The British HIV Association (BHIVA). 2008: UK national guidelines for HIV testing. London: British HIV Association.
Cant, B. 2002: An exploration of the views of gay and bisexual men in on London borough of both their primary care needs and the practice of primary care practitioners. Primary Health Care Research and Development 3, 124-30.

Cohen, J., Lo, Y., Caceres, C. and Klausner, J. 2013: WHO guidelines for HIV/STI prevention and care amongst MSM and transgender people: implications for policy and practice. Sex Transmitted Infections 89, 536-38.

Health Protection Agency 2011: Time to test for HIV: expanding HIV testing in healthcare and community services in England. London: Health Protection Agency.

Kober, C., Dowson, L., Maher, T., Perry, N., Fisher, M. and Richardson, D. 2010: A qualitative study to explore why individuals who are late presenters with HIV infection do not test sooner. HIV Medicine 11, 109.

Koester, K., Collins, S., Fuller, S., Galindo, G., Gibson, S and Steward, W. 2013: Sexual healthcare preferences among gay and bisexual men: a qualitative study in San Francisco, California. PLoS One 8, 8 .

Lowe, M. and Huebner, D. 2010: Does having a primary care provider increase HIV screening among men who have sex with men (MSM)? American Journal of Epidemiology $171,156$.

National Institute for Clinical Excellence (NICE). 2010. NICE good practice guidelines on promoting uptake of $H I V$ testing for MSM. London: National Institute for Clinical Excellence.

National Institute of Clinical Excellence (NICE). 2012: HIV testing: increase uptake in men who have sex with men. London: National Institute of Clinical Excellence.

Petroll, A. and Mosack, K. 2011: Physician awareness of sexual orientation and preventive health recommendations to men who have sex with men. Sex Transmitted Infection 38, 63-67.

Public Health England 2014. Addressing late HIV diagnosis through screening and testing. London: Public Heath England.

Sigma Research. 2016: State of play: England's gay men's sex survey 2014. London: Sigma Research.

Wallace, L. and McDaid, J. 2014: HIV prevalence and undiagnosed infection among a community sample of gay and bisexual men in Scotland, 2005-2011: implications for HIV testing policy and prevention. PLoS One 9, 3.

Wood, H., Colver, H., Stewart, E. and Palfreeman, A. 2011: Increasing uptake of HIV tests in men who have sex with men. Practitioner 1739, 25-28. 